\title{
Consideraciones críticas de las posibilidades de empleo y rendimiento del intercambiador de calor por suspensión en gases
}

O. KUNZE, Ing. Grad.

Humboldt Wedag Española, S. A.

\begin{abstract}
AGRADECIMIENTO
Mucho nos complace agradecer al Instituto Eduardo Torroja la invitación para participar en estos coloquios, $y$ a todos los presentes el interés demostrado con su asistencia a la ponencia.
\end{abstract}

\section{INTRODUCCION Y DESCRIPCION}

El intercambiador de calor por suspensión en gases, de cuatro etapas, está destinado a someter el crudo de cemento a un tratamiento primario antes de su entrada al horno rotatorio. Se ofrece ya sólo en Europa por lo menos por cuatro fabricantes de renombre. La primera planta de este tipo operada a escala industrial se instaló en la República Federal Alemana en el año 1950.

El intercambiador de calor, hoy día calificado de convencional, utilizando todo el caudal de gases de escape que se producen en el horno con ocasión de la cocción del clínker, forma, en conjunto con el horno, una sola unidad tecnológica. Aprovechando la energía calorífica de los gases de escape procedentes del horno, cuya temperatura asciende, en la cámara de entrada, a $1.050^{\circ}$ hasta $1.250^{\circ} \mathrm{C}$, se somete el crudo, hasta su entrada al horno, a un calentamiento hasta $780^{\circ}$ a $830^{\circ} \mathrm{C}$, con cuya ocasión experimenta una desacidulación hasta de un $60 \%$. Al objeto se reconduce el crudo cuatro veces al interior de los conductos de gases de escape que establecen la unión entre las diversas etapas de ciclones y la cámara de entrada al horno.

El separador de doble ciclón de la etapa I y los tres ciclones dispuestos a continuación, en el sentido de flujo del crudo, forman las cuatro etapas del intercambiador de calor de conducto único. En un sistema de construcción gemela se conectan dos conductos de intercambiador de calor a una única cámara de entrada. El tratamiento primario del crudo en las etapas considera que los períodos de calentamiento para las partículas de cru- 
do en el flujo de gases, de 0,1 hasta 0,3 segundos, pueden ser sobrepasados para fracciones de granulometría gruesa de crudos preparados industrialmente y por originarse aglomeraciones de crudo.

En caso de una fuerte concentración de crudo existe la posibilidad que mayores partículas ya sean separadas en el ciclón, antes de alcanzar las mismas la temperatura de los gases que las rodean (1).

Por repetirse cuatro veces la dispersión en el flujo de gases de escape se garantiza, así pués, que se aprovechan al máximo las posibilidades físicas para conseguir la máxima transmisión posible de calor al crudo. La temperatura de los gases de escape desciende con esta ocasión hasta valores de $300^{\circ}$ hasta $360^{\circ} \mathrm{C}$ delante del ventilador del sistema del intercambiador de calor. Su energía térmica es, sin embargo, todavía suficiente para secar el caudal de materias primas, correspondiente al rendimiento del horno, con una humedad inicial de 8 hasta $9 \% \mathrm{H}_{2} \mathrm{O}$, en sistemas de molturación apropiados al respecto, consiguiendo humedades residuales inferiores a $1 \% \mathrm{H}_{2} \mathrm{O}$.

Esenciales valores de servicio del intercambiador de calor se indican en la figura 1 , al lado de la representación del sistema.

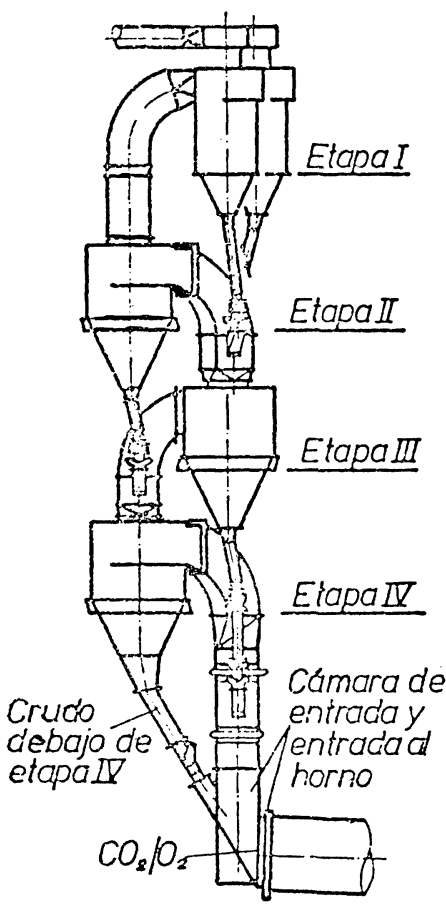

Los datcs de presión mencionados se refieren a una instalación con enfriador de parilla así como a un intercambiador de calor bien entreterido y de dimensiones narmales, con capacidad naminal.

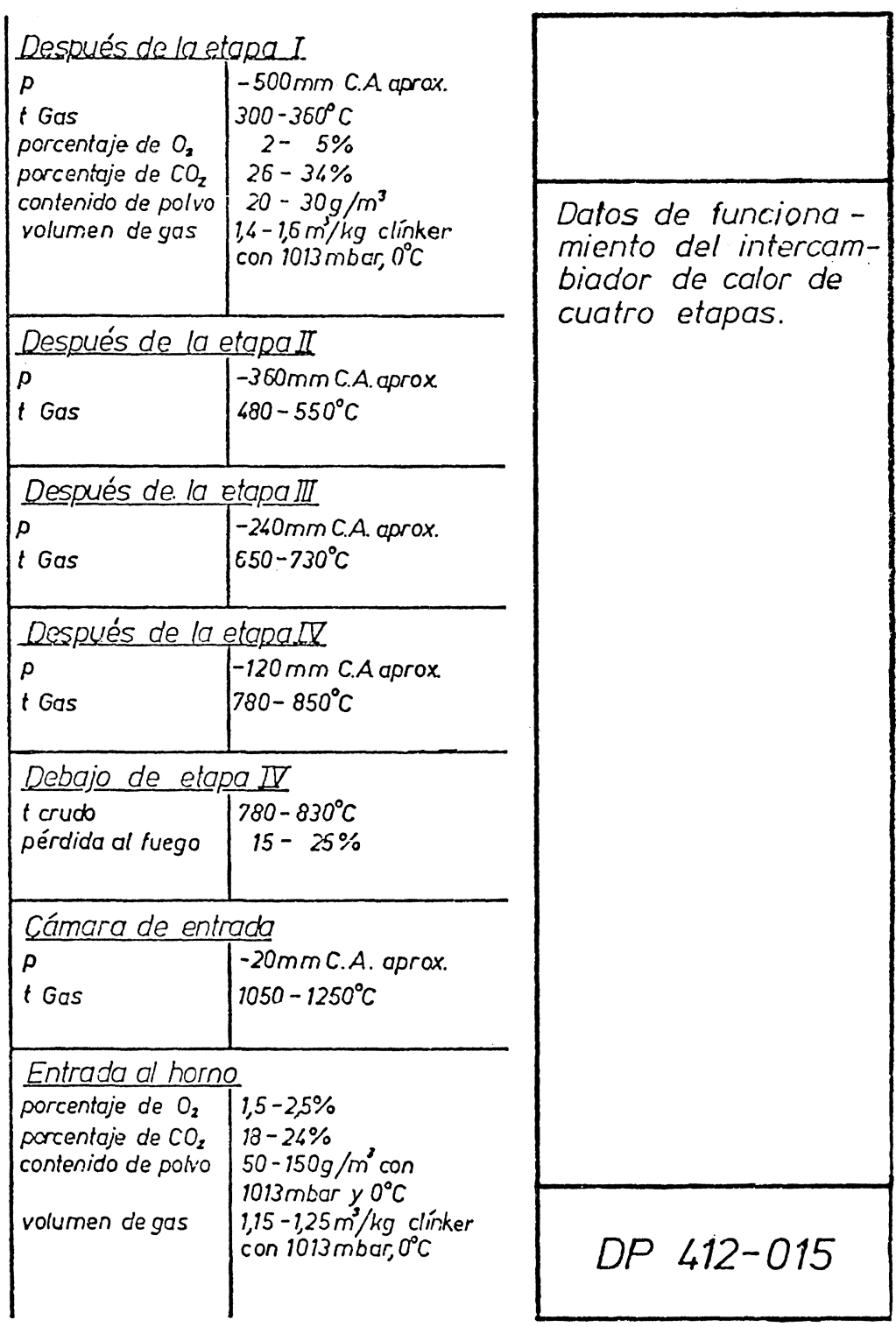

Fig. 1 
El intercambiador de calor del año 1950 (número 1 de la lista de referencias de la KHD Industrieanlagen AG Humboldt Wedag) se construyó con un diámetro de ciclón de 2,8 m, alcanzándose, empleando un horno de $2,5 \mathrm{~m}$ de diámetro y $40 \mathrm{~m}$ de longitud, una producción de clínker de 210 t/día. En el curso del desarrollo para conseguir unidades de equipo de mayor tamaño, y en lo posible también de mayor rentabilidad, se han llegado a construir mientras tanto, en la ejecución de un solo conducto, diámetros de ciclón de $8 \mathrm{~m}$ para una producción de clínker de hasta 4.000 t/día.

Este desarrollo de más de 25 años ha llevado a detalles constructivos y tecnológicos relacionados con el proceso que caracterizan el comportamiento de esta parte de equipo en su funcionamiento, incluso también en comparación con equipos de otros fabricantes. A continuación se consideran algunos de estos detalles. Criterios decisivos con respecto a las formas de construcción representadas fueron, en especial:

- clara separación de los conductos de transporte de gases y de material dentro de las diversas etapas del intercambiador de calor y, con ello, supresión de circuitos de polvo $\sin$ control;

- buena eficiencia de separación de los ciclones a reducida pérdida de presión por considerarse espiras de entrada y trampillas pendulares así como cortos tubos de inmersión y, por tanto, un bajo consumo de energía eléctrica;

- reducida tendencia a perturbaciones por taponamientos, en especial como consecuencia de interrupciones de servicio y situaciones de puesta en marcha, por preverse conductos de crudo ampliamente dimensionados, provistos de trampillas pendulares;

- seguridad de funcionamiento con respecto a averías mecánicas por operación deficiente o equivocada;

- funcionamiento seguro de la planta, incluso al reducirse el caudal de alimentación hasta un $50 \%$.

\section{CONSTRUCCION DEL INTERCAMBIADOR DE CALOR}

\section{Ciclones y tubos de inmersión}

El dimensionamiento de los ciclones se basa en la relación

$\frac{Q^{2}}{S^{5}}=$ constante,

siendo $Q$ el caudal de gases de escape y $S$ el diámetro interior del ciclón o del conducto de gases.

Como constante se considera la pérdida de presión en el sistema, $p=500 \mathrm{~mm}$ columna de agua, por ejemplo para una altura de instalación hasta 500 m s.n.m. A base de estas leyes se puede ya constatar que menores dimensiones de ciclones y, con ello, menor peso del equipo a suministrar, sólo pueden conseguirse, finalmente, si se admiten superiores velocidades de gases y pérdidas de presión y superior consumo de energía por el ventilador del sistema.

Decisivo para la función determinante del ciclón, como elemento separador destinado a separar el crudo del gas portador de energía térmica, sigue siendo la disposición de la espira de entrada a continuación de la tubería de gases ascendiente con el codo. Desemboca, tal como se representa en la figura 2, a través de la mitad de la circunferencia. Anteriores intenciones de conducir la espira por encima de la cuarta parte de la circunferencia o bien colocar el codo directamente en la parte cilíndrica fueron desechadas con- 
siderando el período de duración de los tubos de inmersión y el rendimiento de separación. $\mathrm{Si}$, no obstante, se realizará esta solución, resultará necesario emplear tubos de inmersión, largos también, para las etapas de ciclón III y IV. Los correspondientes materiales resistentes al calor son, sin embargo, también frágiles y no presentan insensibilidad contra temperaturas variantes. Igualmente se cuidará, con ocasión de dimensionar la entrada de gases al ciclón, que el flujo entrante de gases-crudo no llegue a chocar contra el tubo de inmersión, dando allí lugar a desgastes. Con ocasión de realizar tales medidas deberá contarse igualmente con un considerable aumento de la pérdida de presión en cada etapa de ciclón, en una magnitud de aproximadamente $50 \mathrm{~mm}$ columna de agua y aún más.

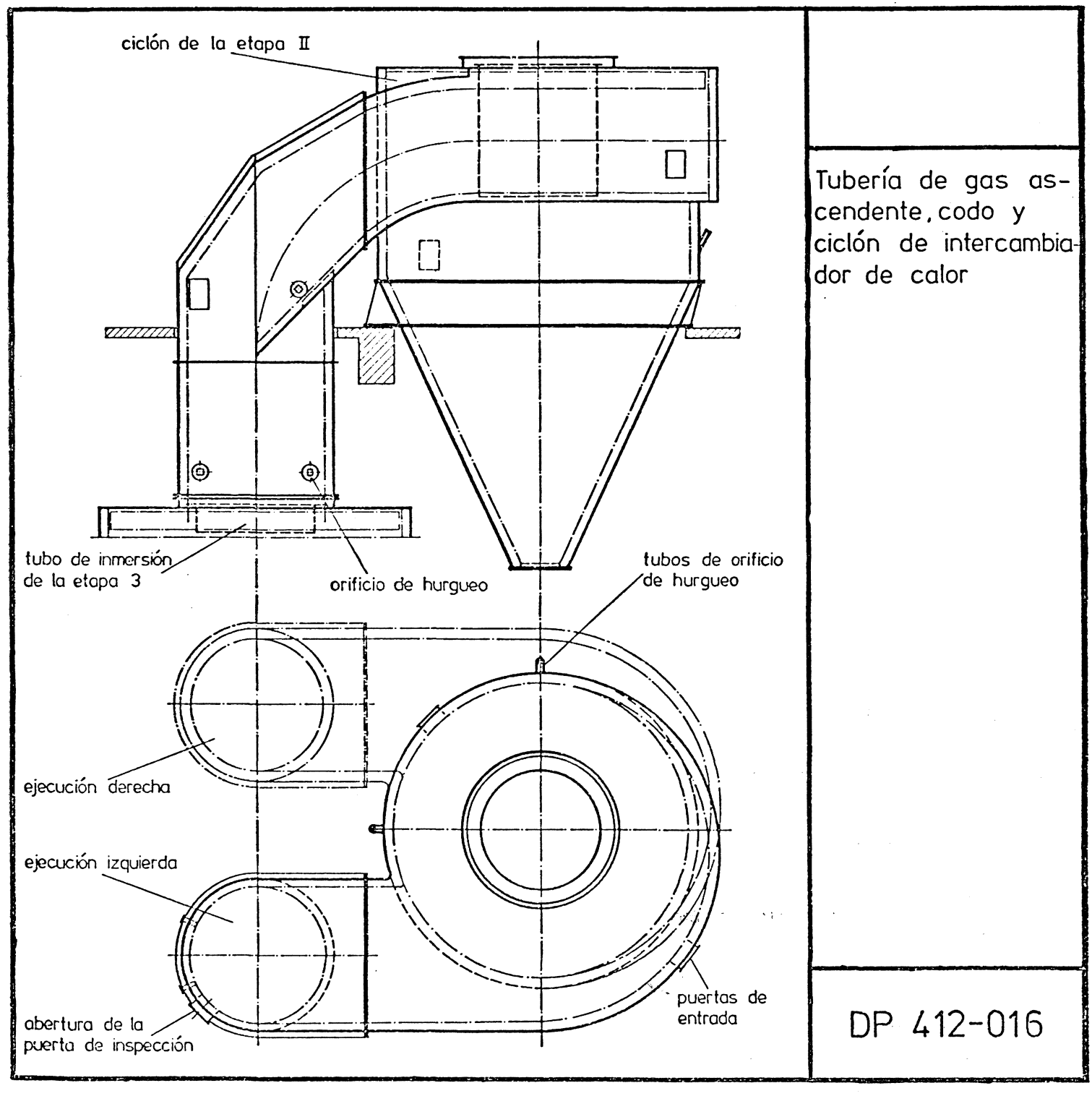

Fig. 2

El empleo de largos tubos de inmersión en el sector inferior del intercambiador de calor, tubos que en caso de avería dan lugar a taponamientos, no corresponde, además, al criterio respecto a seguridad de servicio e insensibilidad en caso de errores de operación, respectivamente, excesivas temperaturas temporales.

La magnitud por la que el diferente dimensionamiento ya repercute, en un equipo del mismo fabricante, sobre el consumo de energía se quiere demostrar en la tabla 1 para plantas con una producción garantizada de 3.000 t/día. 


\begin{tabular}{|c|c|c|c|c|}
\hline Planta n.o & Pérdida de & e presión, mm col. agua & Energía $k W h / t$ de clínker & Observaciones \\
\hline 274 & $\begin{array}{r}517 \\
+\quad 80 \\
\end{array}$ & $\begin{array}{l}\text { para torres de acon- } \\
\text { dicionamiento }\end{array}$ & 10,12 & $\begin{array}{l}\text { torres de acondicionamiento } \\
\text { entre etapa I y ventilado- } \\
\text { res del sistema }\end{array}$ \\
\hline 272 & $\begin{array}{r}394 \\
+\quad 56\end{array}$ & $\begin{array}{l}\text { para torres de acon- } \\
\text { dicionamiento }\end{array}$ & 7,14 & \\
\hline 266 & $\begin{array}{r}650 \\
+\quad 125\end{array}$ & $\begin{array}{l}\text { para torres de acon- } \\
\text { dicionamiento }\end{array}$ & 9,30 & \\
\hline
\end{tabular}

Existen valores que demuestran que se hacen funcionar intercambiadores de calor con pérdidas de presión de $980 \mathrm{~mm}$ col. agua para el transporte de gases desde la cámara de entrada hasta el ventilador del sistema.

\section{Separador de doble ciclón}

Diferenciándose de la construcción de las etapas de ciclón único II hasta IV se construye, al objeto de asegurar máxima separación de gases y de crudo, la etapa I siempre a base de un doble ciclón.

Con respecto al rendimiento de separación, cuentan los encargados de producción con una pérdida en forma de polvo que llega hasta $6 \%$ del caudal de crudo alimentado. Mediciones en funcionamiento para demostración de garantías de las plantas mostraron pérdidas de polvo alrededor de $4 \%$. No pudiéndose desechar operaciones equivocadas, hasta incluso manipulaciones en los contactos de máxima del seguro para controlar las temperaturas, se consideró, con la ejecución representada en la figura 3 de un separador de doble ciclón con forro de mampostería, también el hecho de que la torre de acondicionamiento para los gases se dispone, al existir determinadas humedades de las materias primas, entre la etapa de ciclón I y el ventilador del intercambiador de calor, dejando así de producir efecto la desconexión del ventilador del intercambiador de calor al alcanzarse la temperatura máxima. En este caso deberá traspasarse la función de desconexión a la temperatura detrás de la etapa I (como máximo de $500^{\circ} \mathrm{C}$ ).

El forro refractario del separador de doble ciclón se coloca con un espesor de $125 \mathrm{~mm}$ en la punta de salida, de $65 \mathrm{~mm}$ en la parte cilíndrica (a partir de ciclón de tamaño 3,3 metros de diámetro) y de $125 \mathrm{~mm}$ en el techo suspendido. Para este último se prevé el empleo de ladrillos de forma, de chamota dura, icon 25 hasta $35 \%$ de $\mathrm{Al}_{2} \mathrm{O}_{3}$, observándose una tolerancia de medición máxima de $\pm 1 \%$, y para las demás paredes de material de chamota dura de 25 hasta $30 \%$ de $\mathrm{Al}_{2} \mathrm{O}_{3}$. Estas calidades se emplean, escalonadas en la misma forma, para los techos suspendidos y las capas de desgaste de los ciclones.

\section{Conductos de crudo y cajas de trampillas}

El dimensionamiento y la realización constructiva de los conductos de transporte de material entre las distintas etapas del intercambiador de calor deberá considerarse, con miras a seguridad de funcionamiento, control, y disponibilidad del sistema, con idéntica importancia que la observada para los ciclones y conductos de gases mismos. 


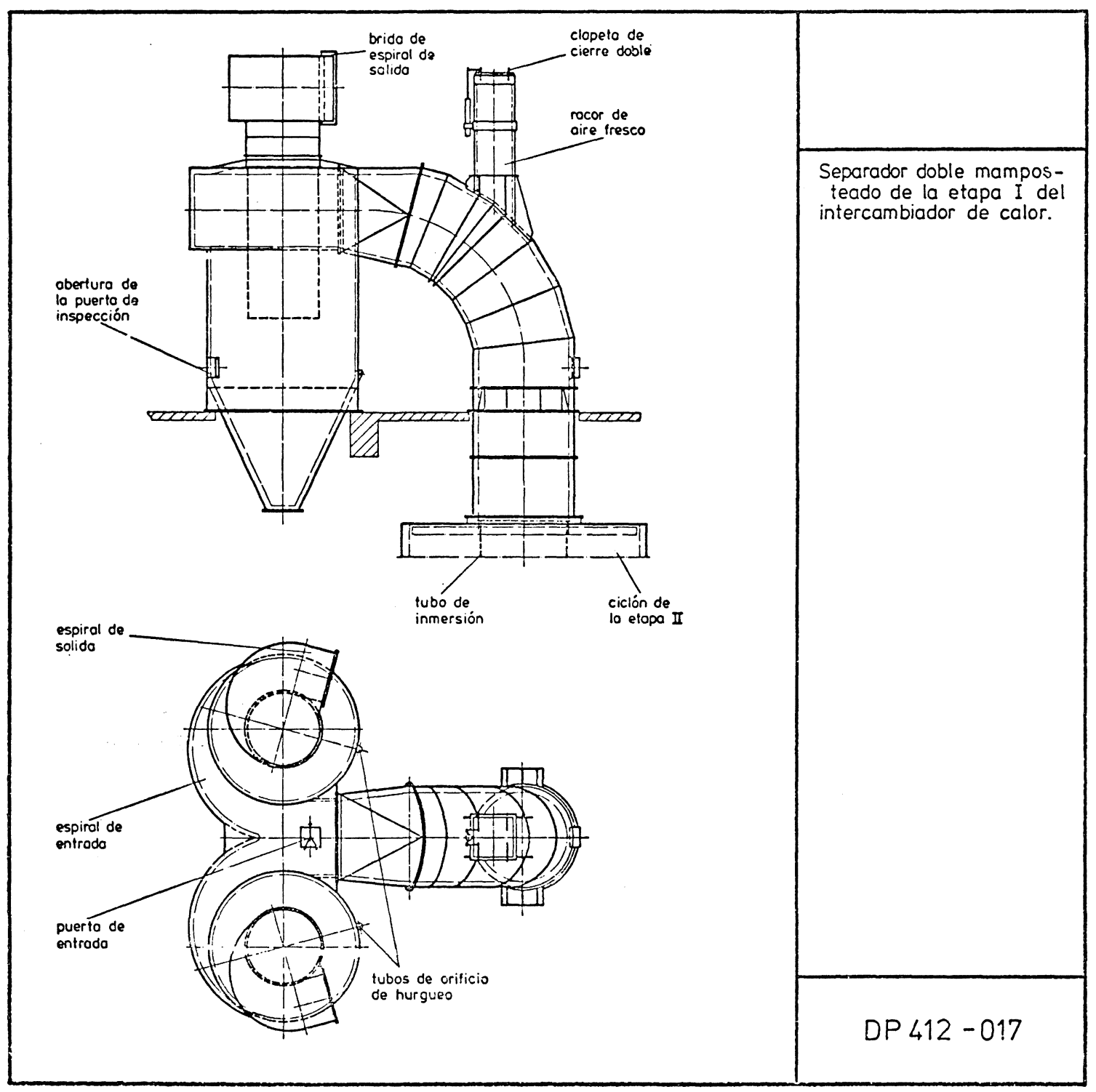

Fig. 3

Los taponamientos en los ciclones se deben, si se reconstruye exactamente el desarrollo del servicio, casi exclusivamente a adherencias de material en el ciclón o en el conducto de crudo con la siguiente resbaladera, preferentemente durante excepcionales situaciones de funcionamiento o en la puesta en marcha. Con esta ocasión se pueden observar, eventualmente, mayores temperaturas de gases en el sistema, temperaturas que - de acuerdo con la figura 1 - quedan de $50^{\circ}$ hasta $150^{\circ} \mathrm{C}$ por encima de las usuales a nivel de producción normal. Al volverse a servicio normal y, con ello a otras temperaturas de ambiente, se desprenden, por ejemplo, tales adherencias de las paredes, interceptando el paso de crudo a la salida del ciclón. Deberá contarse por principio con esta clase de perturbaciones (fallo de corriente, de materiales, etc.). Las consecuencias indicadas y sus influencias sobre la disponibilidad llevaron, en lo que respecta a los conductos de crudo, a los diámetros interiores recopilados en las tablas de las figuras 4, 5 y 6 , en dependencia del tamaño del ciclón. Los conductos bajo las etapas II, III y IV llevan forro de mampostería. Para el forro refractario se prevé primeramente una capa aislante a base de placas sobre base de silicato de calcio o de lana de roca. Como capa de desgaste se emplearán ladrillos de forma, resistentes a la abrasión, con medidas exactas, contenien- 
do de 20 hasta $35 \%$ de $\mathrm{Al}_{2} \mathrm{O}_{3}$, con una resistencia a la compresión en frío de por lo menos $300 \mathrm{kp} / \mathrm{cm}^{2}$, con un peso volumétrico de 2 hasta $2,15 \mathrm{~kg} / \mathrm{dm}^{3}$ y con una tolerancia de medidas de, a lo sumo, $\pm 1 \%$.

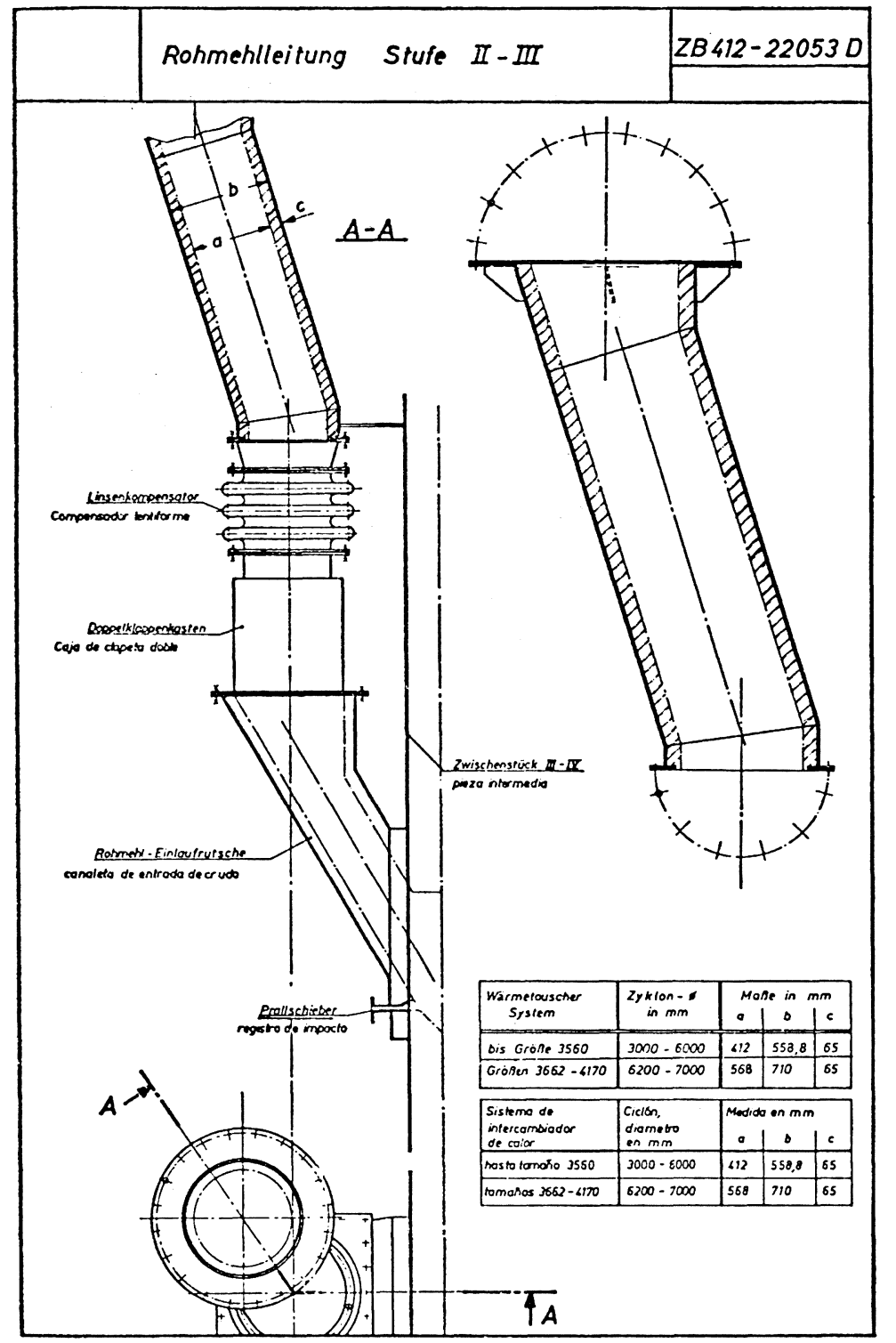

Fig. 4

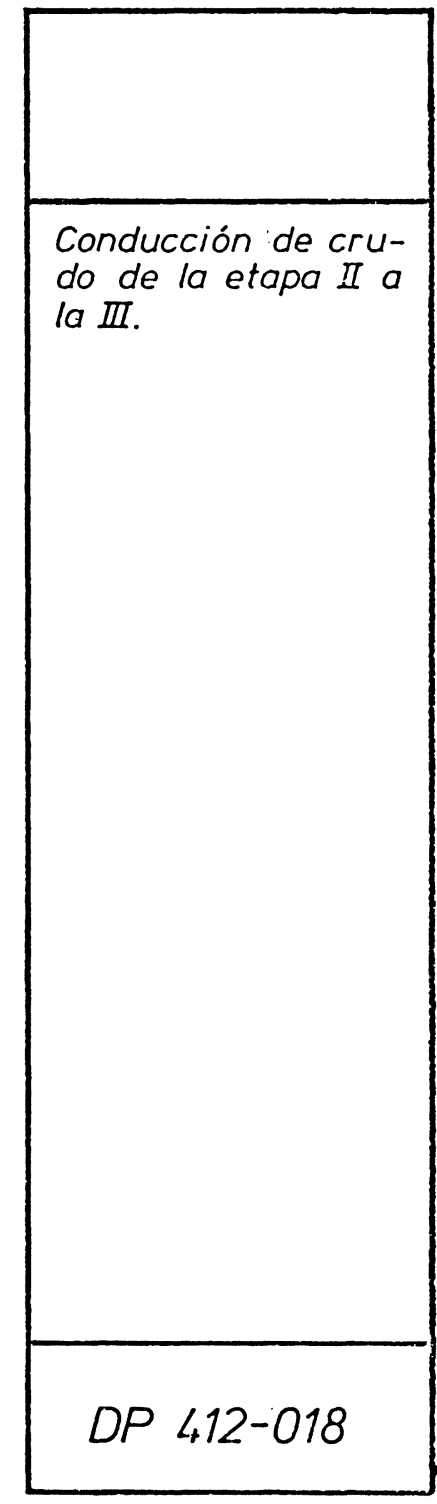

En la medida que lleguen a aplicarse masas colocadas por colada, deberían las mismas mostrar características físicas equivalentes.

En la figura 5 se pueden reconocer, para el conducto bajo la etapa III, los tramos de tubo, cada uno de aprox. 1,5 m de longitud, para la colocación del forro refractario, antes de realizarse el montaje final.

No debe menospreciarse la importancia que tiene sobre el buen funcionamiento del sistema el correcto funcionamiento de las cajas de trampillas al final de los conductos de crudo, respectivamente por encima de las resbaladeras de crudo, las que, en conjunto con las correderas de impacto, producen una alimentación uniforme de material a los conductos de gases contrarrestando:

- durante el servicio de producción: el transporte directo, perjudicial para características de adherencia y calentamiento de material, a través de los conductos de crudo 
y, con ello, la pérdida de un flujo parcial de gases de escape para calentamiento de material y descarbonatación primaria;

- que se afecte la inclinación del torbellino en el ciclón y, con ello, que resulte peor grado de separación;

- en casos de interrupción de la producción y en situaciones de puesta en marcha: un calentamiento excesivo de los conductos de crudo y, consecuentemente, la formación de adherencias en dicho punto.

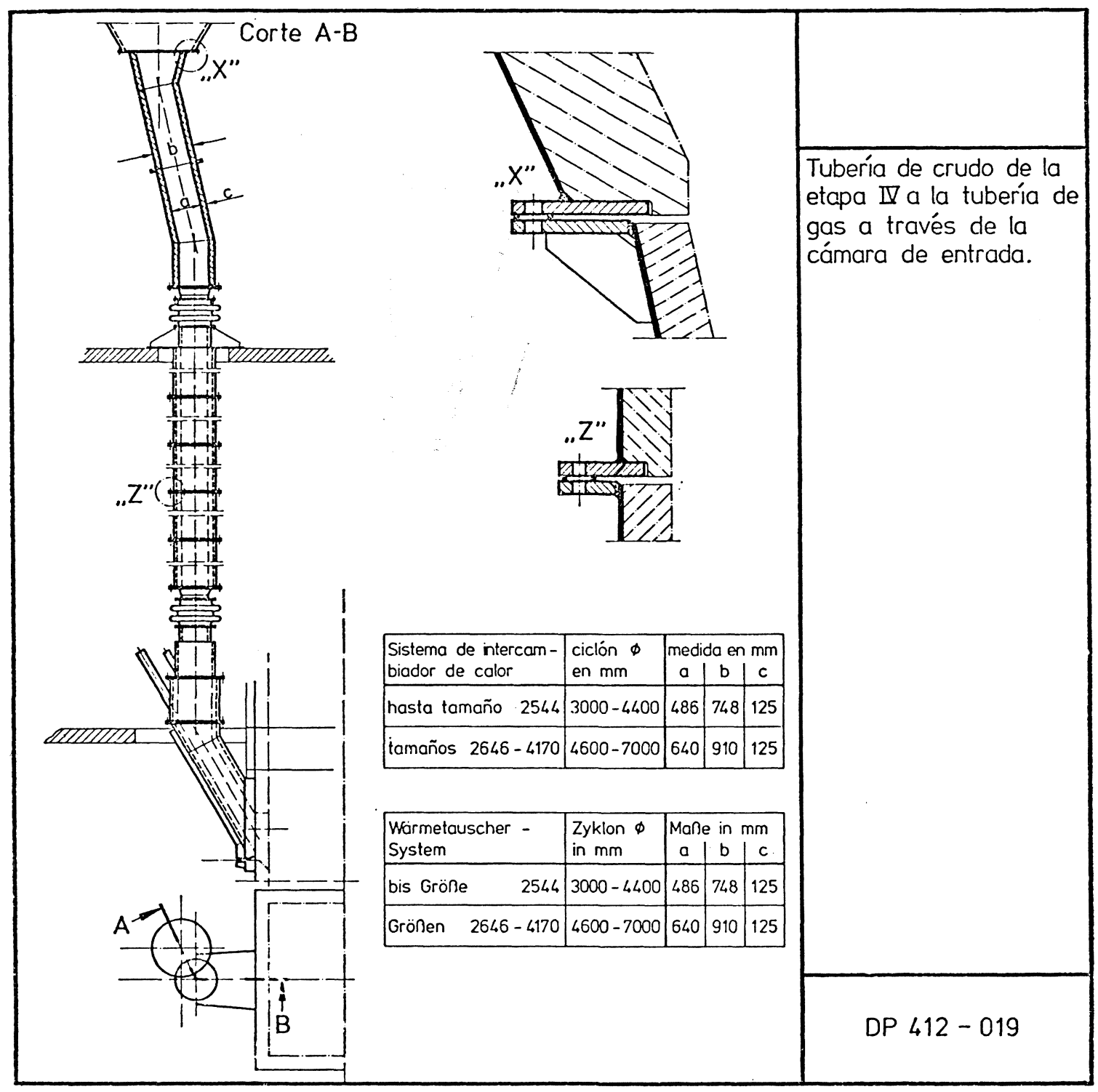

Fig. 5

Permiten, además, al personal encargado de servicio controlar localmente el flujo de material en el intercambiador de calor.

No obstante, se vuelven a presentar siempre de nuevo argumentaciones, insistiendo en desmontar las trampillas para conseguir un funcionamiento supuesto con menos perturbaciones. Punto de partida al objeto es, por ejemplo, la reparación requerida en una trampilla inmovilizada por temperaturas excesivas y por adherencias de material bajo el ciclón IV, la que, de esta forma, se conseguiría de manera "más sencilla". Los resultados unívocos obtenidos en sistemas de intercambiador de calor operados sin trampi- 
llas, en forma de superiores temperaturas de gases de escape, aumentada tendencia de adherencias y menor grado de descarbonatación primaria se oponen, sin embargo, claramente a esta solución. Otra proposición alternativa, la de volver a reducir el diámetro de los conductos sin trampillas pendulares, no se puede calificar como presentada con seriedad en vista de las experiencias descritas, obtenidas en el servicio en más de 300 plantas.
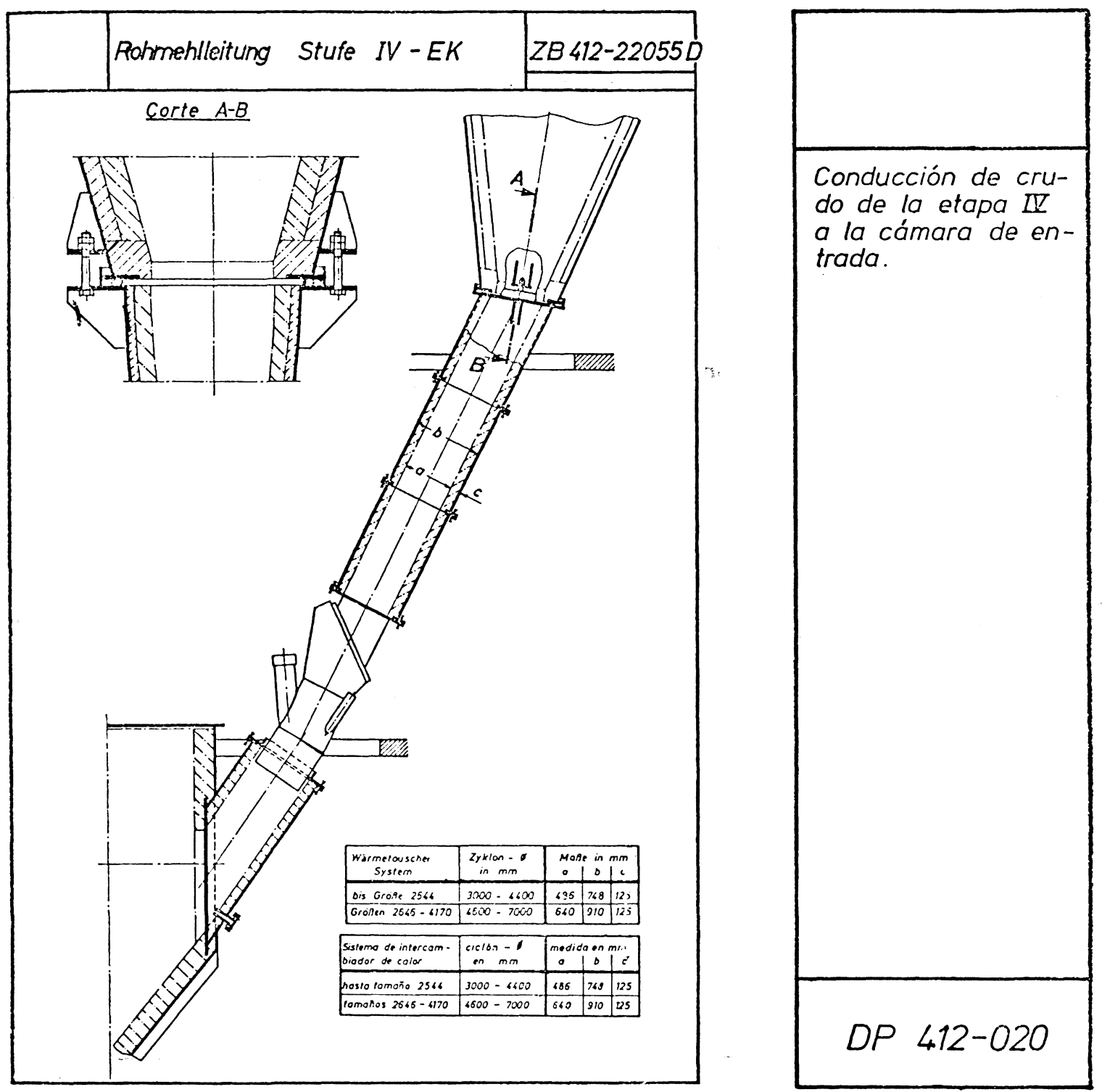

Fig. 6

\section{Desarrollo de los circuitos e incrustaciones en el sector de la cámara de entrada}

Causas principales para que se originen incrustaciones en el sector de la cámara de entrada y del ciclón IV son fenómenos que se desarrollan en los circuitos entre los sistemas horno rotatorio-enfriador e intercambiador de calor. Se diferencia entre circuitos de material condicionados por razones termoquímicas y físico-mecanicas. Igualmente deberán considerarse como factores que producen las incrustaciones, problemas relacionados con la operación del horno, por ejemplo, por desplazamiento del perfil de temperaturas y la división de zonas, así como por errores cometidos en la graduación de la llama y 
en la alimentación de crudo. Al procederse a la calificación de procesos que se originan en los circuitos deberá considerarse que, finalmente, sólo sirven para investigación química aquellas pruebas de material que se obtengan por extracción o por aspiración durante el servicio continuo. De acuerdo con su frecuencia se deben diferenciar, en especial, 3 tipos de circuitos:

- circuitos de cloruros alcalinos $(\mathrm{KCl}$ y $\mathrm{NaCl})$;

- circuitos de sulfatos alcalinos $\left(\mathrm{K}_{2} \mathrm{SO}_{4}, \mathrm{Na}_{2} \mathrm{SO}_{4}\right)$;

- circuitos de $\mathrm{SO}_{3}\left(\mathrm{SO}_{2}\right)$.

\section{Circuitos de cloruros alcalinos}

Al existir cloruros alcalinos es de esperar, de acuerdo con nuestras experiencias, que en el horno rotatorio con intercambiador de calor se produzca la evaporación de 98-100\% en la zona de sinterización. No son raras las veces que con esta ocasión se produce una concentración de 50 hasta 100 veces en el crudo a la entrada del horno en comparación con los valores de entrada de las materias primas.

Fueron demostrados ya valores superiores a $10 \% \mathrm{de}^{-}$en el crudo pasante por debajo de la etapa IV, con cuya ocasión se sobreentiende que ya no es más posible mantener un servicio continuo.

Para salvar este problema se instala una desviación parcial de gases en el sector de la cámara de entrada del intercambiador de calor. La cantidad de gases a desviar depende de la cantidad de cloruros en el crudo alimentado y de la cantidad de $\mathrm{Cl}^{-}$considerada como admisible en el crudo caliente, a la entrada del horno. La experiencia ha demostrado que para evitar taponamientos de ciclones se tienen que mantener valores de, a lo sumo, 1,5 hasta $2 \%$ de $\mathrm{Cl}^{-}$, y para evitar extensamente incrustaciones en la cámara de entrada de, a lo sumo, $0,5 \% \mathrm{de}^{-}$. El punto esencial es en esto que se eviten taponamientos de ciclones, ya que eventuales incrustaciones de cloruros que se produzcan se pueden quitar, contrariamente a lo que ocurre con incrustaciones de sulfatos, de forma relativamente fácil, durante el mismo servicio.

\section{Circuitos de sulfc.tos alcalinos}

Al trabajarse con temperaturas de zona de sinterización y composiciones de crudo correspondientes a valores normales, los sulfatos alcalinos son evacuados en gran escala en conjunto con el clínker, sin que lleguen a evaporizarse y se produzca su recirculación.

Esto rige en especial para el sulfato sódico. Sulfato potásico llega a concentrarse bajo la etapa de ciclón IV en la medida que aumenta la temperatura de la zona de sinterización y descendiendo los contenidos en fase de fusión en el clínker por 1,5 hasta 4 veces, sin que, sin embargo, lleguen a producirse en la mayoría de los casos perturbaciones del servicio continuo de las instalaciones.

En casos donde se producen problemas por incrustaciones existe la posibilidad de intercalar una corredera de choque en el conducto de entrada de crudo y producir así una circulación de crudo entre cámara de entrada y ciclón IV. De esta forma se consigue que los compuestos alcalinos, que llegan desde el horno en forma de gases o de neblinas, queden obligados a adherirse a partículas de crudo en suspensión, relativamente frías, solidificándose allí, antes de que puedan entrar en contacto con las paredes de la cámara de entrada. Un efecto negativo es que, por una parte, se afecta la descarbonatación del crudo en el intercambiador de calor y, por otra parte, se produce un aumento de la pérdida de presión, ya que en tal caso se tiene que rendir mayor trabajo de transporte neumático. Ambos factores llevan a que se reduzca el rendimiento punta de la planta y, en 
caso extremo, a un funcionamiento no constante del horno. Estas deficiencias, sin embargo, apenas se manifiestan si, intencionadamente, se mantiene reducida la cantidad de crudo circulante. Esto se puede conseguir, fácilmente, modificando la posición de la corredera durante el servicio. La conducción de esta corredera de impactos se puede reconocer, en la figura 6, en el extremo inferior del tubo de entrada de crudo provisto de forro de mampostería.

\section{Circuitos de $\mathrm{SO}_{3}\left(\mathrm{SO}_{2}\right)$}

Experiencias obtenidas en los últimos años han demostrado, de forma bien clara, que al existir azufre procedente del crudo y del combustible resultan grandes dificultades por incrustaciones de bastante espesor, con taponamientos, si no existen suficientes álcalis que se encarguen de la fijación del azufre.

$\mathrm{El} \mathrm{SO}_{3}\left(\mathrm{SO}_{2}\right)$ libre llega a unirse, en el sector de entrada del horno y en el intercambiador de calor, con la cal libre allí existente, formando sulfato cálcico de las más distintas formas mineralógicas (por ejemplo, $2 \mathrm{CaO} . \mathrm{SO}_{3}, 2 \mathrm{CaO} . \mathrm{SO}_{3} \cdot \mathrm{SiO}_{2}$ ), que tienen un punto de fusión bajo y que, en función de la temperatura de sinterización y de la granulación de clínker en la zona de sinterización, pueden volver a disociarse.

Una reducción de circuitos de $\mathrm{SO}_{3}$ por medio de una desviación parcial de gases no se puede justificar casi nunca desde el punto de vista económico, ya que las cantidades de azufre introducidas con las materias primas o con el combustible sobrepasan de 10 hasta 50 veces las introducciones comparables de cloruro. Esto implica una evacuación parcial de gases, en la magnitud de $15 \%$ frente a aprox. $5 \%$ en un circuito de álcalis.

Al verificarse el exceso de $\mathrm{SO}_{3}, \mathrm{SO}_{3}$ total $-\mathrm{SO}_{3}$ combinado a $\mathrm{Na}_{2} \mathrm{O}$ y $\mathrm{K}_{2} \mathrm{O}$-, el exceso debería quedar, de acuerdo con el cálculo estequiométrico, referido al clínker, por debajo de $0,3 \%$. Existiendo un exceso de azufre se comprobará primeramente si, disminuyendo azufre en las materias primas o combustible o bien añadiendo aditivos ricos en óxidos alcalinos - especialmente con elevado contenido de $\mathrm{Na}_{2} \mathrm{O}$ y, en la medida que esto es tolerable por la calidad del clínker-, se puede obtener un remedio al respecto.

$\mathrm{Si}$, por el momento, no se pudiera obtener ninguna solución de esta forma, se deberá considerar a continuación la creación de un circuito de polvo.

En dos plantas se trabaja, por ejemplo, con un circuito de polvo en el servicio de producción continuo, con excesos de $\mathrm{SO}_{3}$, de 0,55 y $0,6 \%$ respectivamente, referidos a clínker.

A título de ejemplo para la concentración de $\mathrm{SO}_{3}, \mathrm{Cl}^{-}, \mathrm{K}_{2} \mathrm{O}$ y $\mathrm{Na}_{2} \mathrm{O}$ en el servicio de producción y detrás del by-pass, con un caudal parcial de gases de $5,8 \%$, se indican en la tabla 2 los valores correspondientes a una planta para 1.100 t/día de clínker.

TABLA 2

\begin{tabular}{|c|c|c|c|c|c|}
\hline & $\begin{array}{l}\mathrm{SO}_{3} \\
(\%) \\
\end{array}$ & $\begin{array}{c}\text { Pérdida al } \\
\text { fuego } \\
(\%)\end{array}$ & $\begin{array}{l}\mathrm{Cl}^{-} \\
(\%) \\
\end{array}$ & $\begin{array}{l}\mathbf{K}_{2} \mathrm{O} \\
(\%) \\
\end{array}$ & $\begin{array}{l}\mathrm{Na}_{2} \mathrm{O} \\
(\%) \\
\end{array}$ \\
\hline Crudo alimentado & 0,42 & 35,6 & 0,015 & 0,52 & 0,19 \\
\hline Crudo bajo etapa II & 0,75 & 34,4 & 0,360 & 0,52 & 0,08 \\
\hline Crudo bajo etapa III & 1,16 & 32,0 & 0,440 & 0,98 & 0,12 \\
\hline Crudo bajo etapa IV & 1,64 & 26,4 & 1,060 & 2,60 & 0,22 \\
\hline Polvo del electrofiltro & $0 ; 9$ & 35,6 & 0,320 & 0,57 & 0,10 \\
\hline $\begin{array}{l}\text { Polvo de los ciclones de seiparación } \\
\text { del equipo by-pass }\end{array}$ & 4,75 & 5,9 & 2,4 & 5,2 & 0.44 \\
\hline $\begin{array}{l}\text { Polvo del gas de escape detrás de } \\
\text { los separadores }\end{array}$ & 5,45 & 14,5 & 9,0 & 32,5 & 1,16 \\
\hline Clínker & 1,1 & - & 0,01 & 0,75 & 0,13 \\
\hline
\end{tabular}




\section{Eficiencia del intercambiador de calor}

Aquí se puede observar repetidamente la tendencia de no discutir el rendimiento de la unidad de 4 etapas en total, sino la eficiencia de etapas de ciclón individuales. Las variaciones resultantes por tal motivo en la entrada de gases a los ciclones (separadores) y manipulaciones en los tubos de inmersión, sin embargo, no son apropiadas para mejorar, de forma demostrada, la descarbonatación primaria del crudo en el intercambiador de calor.

Como criterios de evaluación deben citarse:

- tratamiento, sin problemas, de los gases de escape del horno rotatorio, con temperaturas que alcanzan hasta $1.300^{\circ} \mathrm{C}$;

- magnitud de la pérdida de gases de escape y, así pues, de la temperatura detrás del intercambiador de calor;

— descarbonatación primaria, esencialmente del crudo antes de su entrada al horno.

\begin{tabular}{|c|c|c|c|}
\hline \multirow{11}{*}{$\begin{array}{l}\text { Porcentaje de combustible en } \\
\text { el intercambiador de calor } \\
\text { aprox. un } 20 \%\end{array}$} & \multirow{3}{*}{\multicolumn{2}{|c|}{ 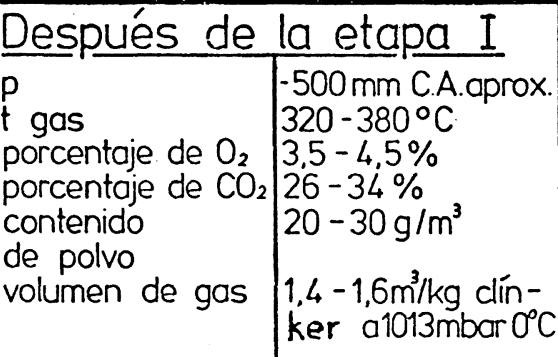 }} & \\
\hline & & & \multirow{9}{*}{$\begin{array}{l}\text { Datos de } \\
\text { funcionamiento } \\
\text { del intercambia- } \\
\text { dor de calor de } \\
\text { cuatro etapas } \\
\text { con Pyroclon, S" }\end{array}$} \\
\hline & & & \\
\hline & \multicolumn{2}{|c|}{\begin{tabular}{l|l} 
Después de la etapa II \\
p \\
t gas & $\begin{array}{l}-360 \mathrm{~mm} \text { C.A. aprox. } \\
520-580^{\circ} \mathrm{C}\end{array}$
\end{tabular}} & \\
\hline & \multicolumn{2}{|c|}{\begin{tabular}{|l|l|}
\multicolumn{2}{|c|}{ Después de la etapa III } \\
p & $\begin{array}{l}-240 \mathrm{~mm} \text { C.A.aprox. } \\
700-780^{\circ} \mathrm{C}\end{array}$
\end{tabular}} & \\
\hline & \multicolumn{2}{|c|}{\begin{tabular}{l|l} 
Después de la etapa IV \\
p \\
t gas & $\begin{array}{l}-120 \mathrm{~mm} \text { C.A.aprox. } \\
800-870^{\circ} \mathrm{C}\end{array}$
\end{tabular}} & \\
\hline & \multicolumn{2}{|c|}{\begin{tabular}{|l|l} 
Debajo de etapa IV \\
$\begin{array}{l}\text { t crudo } \\
\text { pérdida al } \\
\text { fuego }\end{array}$ & $\begin{array}{l}800-840^{\circ} \mathrm{C} \\
12-22 \%\end{array}$ \\
\end{tabular}} & \\
\hline & \multirow{2}{*}{\multicolumn{2}{|c|}{ 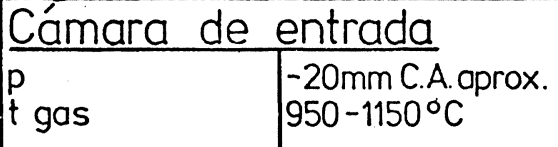 }} & \\
\hline & & & \\
\hline & \multirow{2}{*}{\multicolumn{2}{|c|}{\begin{tabular}{|l|l|l|l|} 
Entrada al horno \\
pcrcentaje de $\mathrm{O}_{2}$ & $3,5-4,5 \%$ \\
porcentaje de $\mathrm{CO}_{2}$ & $16-22 \% \%$ \\
contenido de & $50-150 \mathrm{~g} / \mathrm{m}^{3} \mathrm{a}$ \\
polvo & $1013 \mathrm{mbar}, 0^{\circ} \mathrm{C}$ \\
cantidad de gas & $\begin{array}{l}1,1-1,2 \mathrm{~m}^{3} / \mathrm{kg} \text { clínker } \\
\text { a } 1013 \mathrm{mbar}, 0^{\circ} \mathrm{C}\end{array}$ \\
\end{tabular}}} & \\
\hline & & & DP. $412-014$ \\
\hline
\end{tabular}

Fig. 7 
Según nuestro criterio se originan las fases tecnológicas requeridas para calentamiento del material y descarbonatación, así como calcinación casi exclusivamente en los conductos de gases hacia los ciclones. Indicaciones en la literatura correspondientes, respectivas a la fábrica de cemento soviética Spassky, para un intercambiador de calor de 4 etapas, de ejecución sin detallarse exactamente, citan que $80 \%$ del intercambio térmico se produce en los tubos de ascensión de gases y solamente $20 \%$ en los ciclones (1).

Las pérdidas al fuego experimentadas por el crudo bajo la etapa IV, citadas en la figura 1, corresponden a descarbonataciones de 57 hasta $29 \%$. A una temperatura de gases de escape de $300^{\circ} \mathrm{C}$ se puede contar con una pérdida de gases de escape de $150 \mathrm{kcal} / \mathrm{kg}$ de clínker. Los valores alcanzados por la pérdida al fuego dependen, finalmente, de la temperatura máxima de gases en la cámara ide entrada, temperatura que todavía puede tolerarse teniendo en cuenta el comportamiento con respecto a incrustaciones. Una descarbonatación adicional del crudo antes de su entrada al horno, existiendo un intercambiador de calor, es sólo posible por alimentación complementaria de combustible al conducto de gases por encima de la cámara de entrada. La proporción de combustible quemado con tal ocasión frente al total de combustible es de hasta $25 \%$. El sistema del segundo punto de calefacción se realizó por Humboldt en siete plantas de producción, de las cuales ya están funcionando cuatro. Los valores de servicio determinados con tal ocasión se desprenden de la figura 7.

\section{Calcinación y repercusión sobre las dimensiones del horno}

Una gran influencia sobre el dimensionamiento del horno tienen los límites establecidos por la tecnología de la calcinación en suspensión. Resultados obtenidos en la operación de plantas con esencial descarbonatación en el intercambiador de calor confirman un aumento de las pérdidas de gases de escape de hasta $40 \mathrm{kcal} / \mathrm{kg}$ de clínker.

Una aclaración teórica de este fenómeno se da por B. Vosteen (2), según la cual la descarbonatación de una partícula de caliza depende de los parámetros:

- temperatura de descarbonatación;

- período de permanencia de las partículas en la etapa de calcinación;

- granulometría de las partículas.

Sobre la granulometría y curva granulométrica de un crudo producido a escala industrial, sólo se puede influir en estrechos límites y tampoco es posible producir un "crudo de granulometría única". Además no pueden evitarse procesos de aglomeración en el crudo.

El tiempo de permanencia de las partículas en la etapa de calcinación de un intercambiador de calor por suspensión en gases no puede extenderse por más de algunos pocos segundos. La fracción de granulometría más gruesa del crudo implica, sin embargo, a temperaturas de $850^{\circ}-900^{\circ} \mathrm{C}$, períodos de descarbonatación que corresponden, por lo menos, a un valor elevado a la décima potencia.

Una correspondiente alternativa, para lograr elevados grados de calcinación en el intercambiador de calor, el de aumentar el caudal térmico ofrecido, reproduce un aumento de las pérdidas de gases de escape. Estas pérdidas pueden volverse a reducir parcialmente por emplearse una quinta etapa de intercambiador de calor, aumentando por otra parte los gastos de inversión y por consumo de energía. Se considera, sin embargo, más práctico y más económico realizar la descarbonatación restante de la fracción granulométrica más gruesa en el mismo horno rotatorio, limitando de esta forma la descarbonatación en el intercambiador de calor a la fracción de finos en el crudo. 
Así se pueden mantener reducidas las pérdidas de gases de escape.

A base de las consideraciones aquí citadas, ha combinado Humboldt las posibilidades que ofrece la tecnología de aplicar un segundo punto de calefacción, de forma que, a base de los gastos de inversión y de operación, resulta un coste mínimo de producción.

Con esta ocasión se denomina el calcinador al que se conduce el aire de combustión (aire terciario) por el tubo rotatorio "Pyroclon S" (especial), y el calcinador al que se conduce el aire terciario por medio de su propio conducto de aire "Pyroclon R" (regular).

La figura 8 muestra, para capacidades de plantas de 1.000 hasta 8.000 t/día, las respectivas posibilidades de construcción que considera los criterios antes citados.

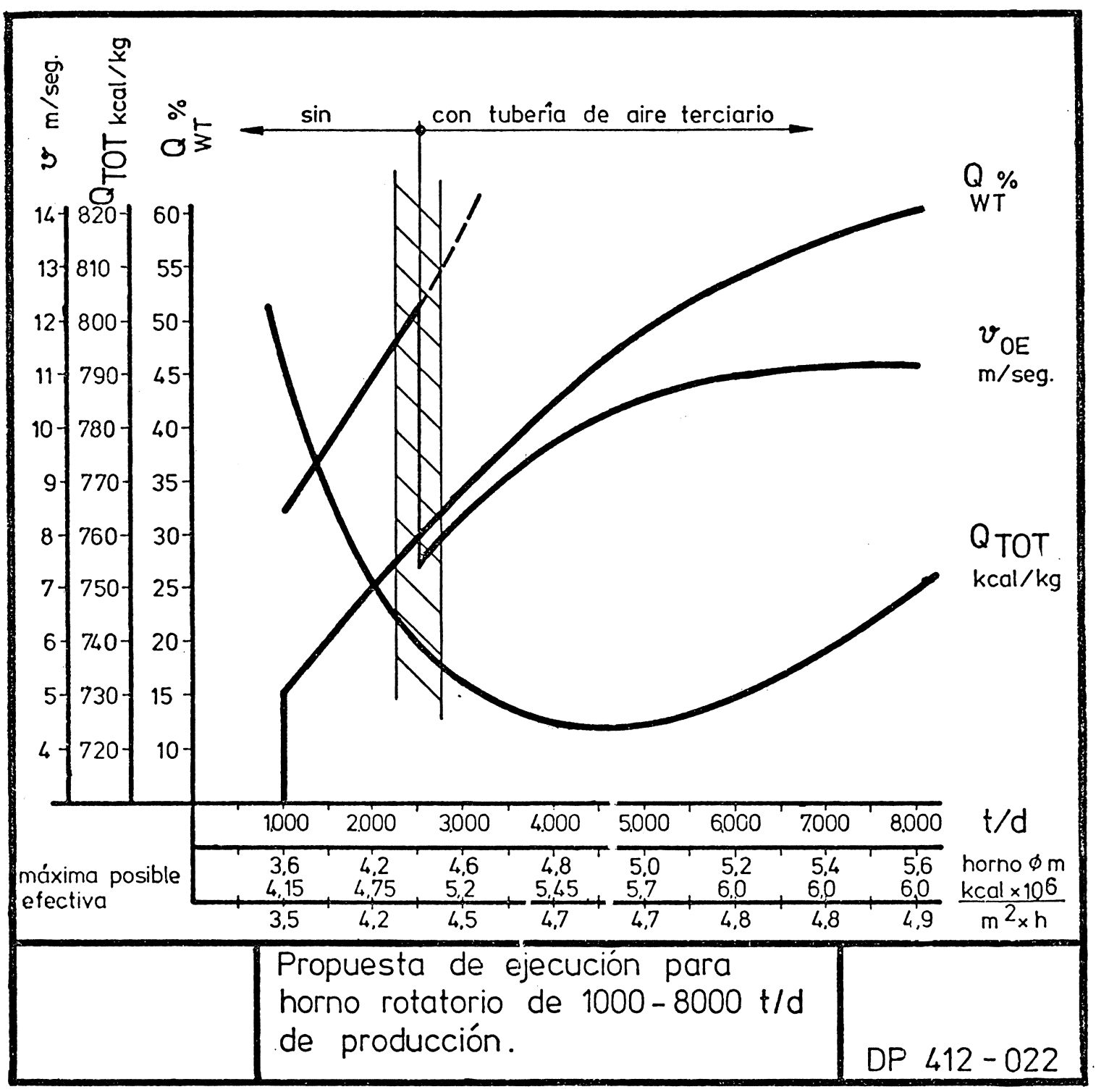

Fig. 8

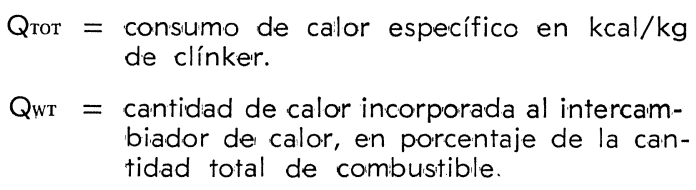
de clínker.

QWT $_{\text {W }}$ cantidad de calor incorporada al intercambiador de calor, en porcentaje de la cantidad total de combustible.

$$
\begin{aligned}
V_{O E}= & \begin{array}{l}
\text { velocidad del gas a la entrada del horno } \\
\text { en } \mathrm{m} / \mathrm{s} .
\end{array} \\
t / \mathrm{d}= & \begin{array}{l}
\text { producción de clínker en toneladas dia- } \\
\text { rias. }
\end{array}
\end{aligned}
$$


Se pueden deducir diámetro de horno, magnitudes de calefacción adicional en el intercambiador de calor, carga de la zona de sinterización, velocidad de gases en la entrada al horno, así como conducción de aire terciario, para cualquier capacidad de producción.

Con esta ocasión se espera obtener un consumo calorífico como indicado, dependiente del tamaño de la planta y del caudal de combustible en el intercambiador de calor (3).

Se puede reconocer que, al efectuarse calefacción en el segundo punto, con dosificación óptima, es posible conseguir, en plantas con una producción entre 4.000 y $5.000 \mathrm{t} /$ día un consumo mínimo calorífico, con cuya ocasión el diámetro del horno $(4,8$ hasta $5 \mathrm{~m})$ y la carga en la zona de sinterización $\left(4,7 \times 10^{6} \mathrm{kcal} / \mathrm{hm}^{2}\right)$ permiten considerar valores favorables respecto a gastos por desgaste del forro y buena disposición para utilizar la planta (4).

La conducción de aire terciario influye sobre la posibilidad de utilizar los diversos tipos de enfriamiento de clínker. Así se puede utilizar el enfriador de tubos satélites sólo al existir conducción de aire a través del horno (Pyroclon S), mientras que los enfriadores de parrilla, tubulares y verticales, pueden encontrar aplicación para ambas tecnologías.

\section{NOTA FINAL}

A base de los detalles constructivos descritos y representados para el intercambiador de calor se facilitaron ejemplos y aclaraciones sobre el comportamiento de esta parte de la planta durante su funcionamiento.

Teniendo en cuenta las especiales posibilidades de desarrollo y las proporciones de combustible que deben llegarse a emplear en el intercambiador de calor para efecto de calefacción, merece una mayor importancia el celo a invertirse en la realización constructiva del sistema. A tal objeto es ineludible tener en cuenta y aprovechar las experiencias disponibles y las formas de ejecución realizadas.

\section{B I B L I O G R A F I A}

(1) DudA, W. H.: Cement Data Book, páginas 321-328, Bauverlag GmbH, Wiesbaden y Berlín.

(2) Vosteen, B.: Vorwärmung und vollkommene Kalzination von Zementrohmehl in einem Schwebegassystem. Zement-Kalk-Gips 9, 1974, 443-450.

(3) Herchenbach, H. und KupPeR, A.: Zweitfeuerungen an vierstufigen Zyklonvorwärmern-Ergebnisse und Folgerungen für den Einsatz in bestehenden und neuen Anlagen. Zement-Kalk-Gips 5, 1976, 193197.

(4) ERNI, H.: Betriebserfahrungen mit grossen Drehöfen und Folgerungen für Konstruktion und Überwachung. Zement-Kalk-Gips 10, 1974, 486-498. 
Lo abrió el Presidente Sr. NAVARRO y transcurrió de la forma siguiente:

1. Intervino en primer lugar el Sr. CALLEJA para plantear una cuestión relativa a las concreciones. Parece lógico pensar — dijo- que puede existir, o de hecho existe, una relación entre la formación de adherencias y concreciones de material en determinados puntos del sistema, y las temperaturas en esos mismos puntos. Si esto es así y esa relación se conoce, o se llega a conocer - y ahora viene la pregunta- ¿no sería posible tratar de evitar la formación de esas concreciones y adherencias -o de eliminarlas una vez que se han formado - simplemente haciendo variar desde el exterior, mediante algún procedimiento, la temperatura en esos puntos? Es decir, provocando un desplazamiento de la temperatura, generalmente hacia arriba, con objeto de evitar condensaciones y las consiguientes adherencias, concreciones y taponamientos de material.

Respondió el Sr. KUNZE que él veía estos problemas bajo el aspecto de los servicios de puesta en marcha de las instalaciones de hornos con intercambiadores. Y que al enfrentarse con tales problemas y tratar de reconstruirlos, al final se había encontrado con que siempre se daban circunstancias propicias en las materias primas para formar adherencias y taponamientos.

Y que, asimismo, para evitarlos era necesario, efectivamente, mejorar la carbonatación en el horno, a base de trabajar de forma adecuada con la llama, en particular en épocas de paradas y puestas en marcha de los hornos. En esas épocas — dijo- sucede de vez en cuando que se trabaja con temperaturas inadecuadas, y esa es la razón por la que aparecen las condensaciones del material, las cuales se pueden eludir después de un cierto tiempo, cuando ya se conocen bien los problemas.

2. A continuación el Sr. CORROCHANO indagó acerca de la finura y del caudal de la harina cruda, a lo cual respondió el Sr. KUNZE que la finura se puede cifrar alrededor de un $12 \%$ de residuo sobre tamiz de 4.900 mallas $/ \mathrm{cm}^{2}$. Ciñéndome - dijo-, a materias primas naturales -no "artificiales", como escorias, etc.-, el residuo sobre este tamiz puede elevarse a veces por encima del $14 \%$ y hasta el $20 \%$; ello depende de la cal libre que quede en el clínker, pues ocurre en ocasiones que con residuos algo superiores a 14 ó $15 \%$ aumenta la cal libre porque la temperatura de cocción o la del intercambiador, dado el mayor y más desfavorable tamaño de partículas, no son adecuadas para obtener un clínker de igual calidad y con igual contenido de cal libre; y sí lo serían, si se tratase de un crudo más fino.

Por otra parte - añadió-, un crudo más grueso es más favorable para el funcionamiento del intercambiador, desde el punto de vista de los taponamientos.

A esto dijo el Sr. CORROCHANO que con un crudo más grueso, si la fracción más abundante del mismo es caliza - cosa que no siempre ocurre-, parece que se haría trabajar más al horno, con lo que la temperatura de los gases a la salida del tubo de éste sería más baja. ¿Es así, o no? - preguntó-.

No creo que sea así - dijo el Sr. KUNZE- pues yo he comprobado en muchos casos que las partículas más gruesas son de baja calidad (aceptación de este aserto en términos generales por parte del Sr. CORROCHANO), y que las más finas van a parar 
al electrofiltro. Entonces -añadió-, puede ser que con una harina más gruesa, y sin tener en cuenta el contenido de carbonatos o el estándar de cal, se obtenga un rendimiento mayor.

El Sr. CORROCHANO dijo no estar de acuerdo en esto, y aclaró el punto de vista de su pregunta en el sentido de que, suponiendo que la parte gruesa del crudo posea siempre un estándar de cal más elevado que el resto, cuanto más gruesa sea menor será el intercambio que tenga lugar en los ciclones y mayor la descarbonatación que se produzca en el horno (aceptación de ambas cosas por parte del Sr. KUNZE), y que, como consecuencia, más baja será o podrá ser la temperatura de los gases del tubo del horno.

El Sr. KUNZE admitió que podría ser más baja, pero que el problema está en que no se han ensayado circuitos de control que tengan en cuenta este hecho, y que hay un consenso absoluto en que las partículas más gruesas hacen que la calcinación se traslade al horno, lo cual no es favorable.

El Sr. CORROCHANO aceptó que, desde el punto de vista del rendimiento, en efecto era así, y preguntó si el trabajar con un material excesivamente fino no implicaría aumentar la recirculación de polvo entre el horno y la torre del intercambiador.

A esto respondió el Sr. KUNZE que no creía que se hubieran medido ni que se pudieran medir con exactitud el reflujo y la recuperación de finos, pero que no pensaba que hubiera problema de recirculación elevada, si bien sería bueno poder disponer de un aviso de la descarbonatación en el intercambiador, al operar con crudos más finos.

El Sr. CORROCHANO preguntó después si éstos no creaban mayores problemas de pegaduras en la torre, respondiéndole el Sr. KUNZE que con temperaturaras correspondientes a una marcha de producción normal no había comprobado aumentos del número de adherencias y taponamientos en el intercambiador, y que, en cambio, éstos aumentaban cuando en determinadas épocas de puesta en marcha o de paradas se operaba circunstancialmente con temperaturas excesivas.

3. A continuación el Sr. GARCIA TARRADELLAS pidió aclaraciones acerca de la instalación de una corredera de choque en el conducto de entrada del crudo, para producir una circulación de éste entre la cámara de entrada al horno y el cuarto ciclón, a fin de evitar las incrustaciones.

En su respuesta el Sr. KUNZE se refirió a una de las diapositivas de su exposición, mostrando en ella la solución adoptada hace unos años para evitar problemas de adherencia en la cuarta etapa del intercambiador, en una fábrica en la que no era posible entonces cambiar la composición química del crudo. Solución consistente - dijo-, en instalar un choque de corredera en el sitio indicado, para poder trabajar continuamente y sin interrupciones, con un flujo continuo de material que no es arrastrado por el gas y que en parte es transportado desde la cámara al cuarto ciclón. Con esto -añadió-, se establece un circuito de gases que permite conseguir un mejor equilibrio entre álcalis y sulfatos, así como rebajar en $50-80^{\circ} \mathrm{C}$ (y a veces en $50-100^{\circ} \mathrm{C}$ ) la temperatura de los gases en la etapa cuarta, y reducir la presión en $50 \mathrm{~mm}$ de columna de agua. Esta solución -prosiguió-, no se adopta o se plantea para fábricas nuevas, sino que se ha aplicado a una fábrica en marcha, aprovechando la experiencia de otras plantas. No se pretende - dijo-, trabajar en las condiciones señaladas, porque la disminución de presión y sobre todo de temperatura hacen que el grado de descarbonatación sea menor que el que tiene lugar cuando se trabaja normalmente a 1.200 ó $1.250^{\circ} \mathrm{C}$.

4. El Sr. SARABIA preguntó después sobre las exigencias de calidad de refractarios en la zona de sinterización para cargas térmicas elevadas, interpretando que los valores de la última fila de la diapositiva 8 de la exposición del Sr. KUNZE -3,50, 4,50, 4,90- representaban cargas térmicas en la zona de sinterización. 
El Sr. KUNZE respondió que se había considerado la carga térmica efectiva y la máxima posible, a lo que el Sr. SARABIA dijo que incluso la efectiva la consideraba muy elevada, comparada con la de los hornos corrientes, y preguntó si exigía un refractario especial.

El Sr. KUNZE dijo que las cargas térmicas señaladas eran las mismas con que trabajaban los demás fábricantes de maquinaria, puesto que todos se mueven dentro del mismo rango, y que cuando se tiene que hacer un horno grande, de gran producción, y no demasiado dimensionado, hay que calcular sokrecargas térmicas comprendidas entre los valores indicados.

Insistió el Sr SARABIA en que, entendiendo por carga térmica el calor dividido por la sección útil del horno, los valores dados eran muy altos, comparados con los que él estaba habituado a medir, y preguntó de nuevo si a pesar de ello no hacía falta ningún refractario especial, y si en tales condiciones se comportaba bien uno corriente de magnesita.

Los valores de cargas térmicas dados son los que se tienen en cuenta hoy día - dijo el Sr. KUNZE-, ante la necesidad de reducir el diámetro de los hornos, ya que en los últimos años se ha comprobado que en hornos de diámetros de $5 \mathrm{~m}$ y mayores no se consigue que el refractario se mantenga trabajando continuamente durante un año. Por el contrario -añadió-, es muy corriente que en un horno de 5,3 ó $5.4 \mathrm{~m}$ de diámetro haya que cambiar el refractario de la zona de sinterización al cabo de medio año de marcha. Para evitar esto se trata hoy de hacer que incluso los hornos de gran producción tengan un diámetro, no quiero decir pequeño - dijo el Sr. KUNZE-, pero si lo más justificadamente reducido que sea posible.

Los valores de cargas térmicas de que venimos hablando - preguntó el Sr. SARABIA-, ¿se refieren al calor efectivo del quemador en el horno, o a la suma de este calor más el de la calcinación? A la suma -respondió el Sr. KUNZE-. Entonces - dijo el Sr. SARABIA-, esos valores pueden inducir a una interpretación errónea, porque yo estaba considerando que se referían exclusivamente al quemador del horno, por lo cual me parecían exagerados; pero naturalmente -añadió-, no son efectivos, y de ellos hay que deducir el calor que se está produciendo en el intercambiador -asentimiento del Sr. KUN$\mathrm{ZE}$-, lo que explica que la zona de sinterización pueda trabajar sin necesidad de un refractario especialísimo, como sería preciso con cargas térmicas efectivas de 4 a 4,9.

5. A continuación el Sr. TRIVIÑO, recordando que en la Sesión anterior se había hablado de la conveniencia de añadir yeso o anhidrita al crudo cuando se quema gas natural, por la carencia de azufre de éste, preguntó si en el caso contrario de quemar un fuel-oil con mucho azufre sería favorable y conveniente añadir de alguna forma álcalis a los crudos para evitar las incrustaciones.

El Sr. KUNZE respondió que en la mayoría de los casos ocurre que hay un exceso de álcalis en el crudo, y entonces se añaden sulfatos; pero que si, por el contrario, hay un exceso de sulfatos, es preciso ver en primer lugar si proceden de las materias primas y/o del combustible. En general - dijo-, sucede lo segundo, por lo que hay que controlar el azufre en el fuel-oil, existiendo calidades de éste con contenidos de azufre bastante inferiores a $2 \%$. Dijo tambiéin no creer que fuera un buen remedio añadir álcalis, y se refirió a un caso en el que ezte mismo problema se resolvió haciendo un by-pass de sulfatos, lo cual resulta caro en todo caso, pues exige eliminar por el by-pass, de un 10 a un $15 \%$ del caudal de gases, lo que puede llegar a suponer pérdidas del orden de $100 \mathrm{kcal} / \mathrm{kg}$ de clínker. En la generalidad de los casos - añadió-, se opta por reducir el contenido de sulfatos del crudo, para no tener que añadir álcalis ni recurrir al by-pass de sulfatos. Hay proyectos - concluyó-, que incluyen un by-pass de sulfatos, pero son poco numerosas las realizaciones. 
El Sr. CANUT intervino después, volviendo sobre el tema de la carga térmica del horno, para decir que, en su caso, con un horno DOPOL de $4 \mathrm{~m}$ de diámetro y una carga térmica de alrededor de 5 , el refractario duraba aproximadamente seis meses.

El Sr. KUNZE dijo que, tratándose de un horno de $4 \mathrm{~m}$, cabría esperar una duración algo mayor.

El Sr. CALLEJA reconsideró el aspecto de las dificultades de proceso por adherencia, taponamientos, etc., debidas al ciclo del azufre en el horno. Dijo que cuando hay un exceso de $\mathrm{SO}_{3}$ y faltan en las materias primas álcalis suficientes para fijarlo, claro está que, en principio, una solución podría ser la de añadir al crudo compuestos alcalinos, y precisamente sódicos y no potásicos, ya que éstos últimos crean más dificultades que los primeros. Pero que parecía ser que esta solución, si él no había entendido mal al Sr. KUNZE, era tan mala —o por lo menos igualmente defectuosa- como la del by-pass de gases. Quiere decirse -añadió-, que habiendo exceso de $\mathrm{SO}_{3}$ en los crudos (y en el horno) y no recurriendo a la adición de álcalis ni al by-pass de gases, se puede formar sulfato cálcico, restando cal para las combinaciones normales del clínker, y pudiendo llegar a formarse, incluso, ciertos sulfo-silicatos cálcicos de bajo punto de fusión —o de punto de fusión más bajo que el de los componentes que se forman normalmente cuando tales condiciones de exceso de $\mathrm{SO}_{3}$ no se dan-; y, por supuesto -añadió-, con la consiguiente implicación de todo ello en la formación de adherencias e incrustaciones. A este respecto recabó la información y experiencia del Sr. KUNZE.

Este consideró que sería conveniente leer y aclarar con todo detalle una parte del texto de su exposición, en la que se tocaba este tema. Así se hizo, siendo la lectura resumida la siguiente: "Experiencias de los últimos años han demostrado claramente que, al existir azufre procedente del crudo y/o del combustible, se originan grandes dificultades por formación de incrustaciones de gran espesor y por taponamientos, si no existen al mismo tiempo álcalis suficientes que fijen el azufre. $\mathrm{El} \mathrm{SO}_{3}$ libre llega a combinarse en la zona de entrada del horno y en el intercambiador de calor con la cal libre allí existente, formando sulfato cálcico de las más diversas composiciones y formas mineralógicas - por ejemplo, $2 \mathrm{CaO} \mathrm{SO}_{3}$, o $2 \mathrm{CaO} . \mathrm{SO}_{3} \cdot \mathrm{SiO}_{2}$-, las cuales tienen un punto de fusión bajo y pueden volver a descomponerse, dependiendo de la temperatura de sinterización y de la granulación del clínker, en la zona correspondiente. Una reducción del ciclo de $\mathrm{SO}_{3}$ por medio de una desviación y eliminación parcial y de gases (by-pass) casi nunca se puede justificar desde un punto de vista económico, ya que las cantidades de azufre introducidas con las materias primas y/o con el combustible sobrepasan en 10 a 50 veces las cantidades comparables correspondientes de cloro introducidas; y ello implica una evacuación parcial de gases del orden del $15 \%$, frente a aproximadamente un $5 \%$ en el caso de un circuito de álcalis. $\mathrm{El}$ exceso de $\mathrm{SO}_{3}-\mathrm{SO}_{3}$ total menos $\mathrm{SO}_{3}$ ligado a $\mathrm{K}_{2} \mathrm{O}$ y $\mathrm{Na}_{2} \mathrm{O}$ - debe quedar de acuerdo con el cálculo estequiométrico referido al clínker, por debajo del $0,3 \%$. De no ser así por existir un exceso de azufre, hay que procurar que el contenido de éste en las materias primas y/o en el combustible sea menor, o bien compensarlo por adición de materiales ricos en óxidos alcalinos, con elevado contenido de $\mathrm{Na}_{2} \mathrm{O}$, en la medida en que lo tolere la calidad del clínker. Así, pues, como remedio es posible añadir tales materias, pero con la limitación expresada. En otro caso, se deberá considerar la formación de un circuito de polvo, tal como se hace en dos fábricas en las que el $\mathrm{SO}_{3}$ en exceso, referido a clínker, es de 0,55 y 0,60 \%, respectivamente, con lo cual se puede trabajar de forma continua". He aquí - concluyó el Sr. KUN$\mathrm{ZE}$ - lo que se puede hacer en relación con el asunto planteado por el Sr. CALLEJA.

Y no habiendo más cuestiones que tratar, el Presidente Sr. NAVARRO, dió por concluido el Coloquio, agradeciendo a todos los participantes sus intervenciones.

Sobre el mismo tema de los intercambiadores de calor, y fuera de programa, hubo una breve exposición por parte del Sr. RAMOS, hecha en la Segunda Parte de la Primera 
Sesión sobre PROCESOS, INSTALACIONES Y MAQUINARIA, presidida por el Sr. PEREZ OLEA, y que dió lugar al siguiente Coloquio.

1. Fue iniciado éste por el Sr. SARABIA, el cual dijo que como consecuencia de lo expuesto en las Sesiones sobre AHORRO DE ENERGIA, él -y según creía también otras personas-, habían quedado algo desconcertadas ante la imposibilidad, manifiesta según todas las apariencias, de volver a utilizar carbones para la fabricación de cemento. Y que, en consecuencia, le había producido una gran satisfacción haber escuchado a través de la exposición del Sr. RAMOS que hay quien se preocupa de utilizar carbones incluso malos, lo cual prueba que no es tan pobre un país que es capaz -o intenta serlo-, de aprovechar lo poco que tiene.

2. A continuación el Sr. CALLEJA abundó en el mismo criterio diciendo que los que piensan en la posible necesidad futura de utilizar carbones, incluidos los malos, debían ser considerados tal vez, y más vale -añadió- que la designación profética no se cumpla, como "previsores del porvenir". Pero, por todo ello - continuó-, más que de conveniencia - como se ha hablado aquí- de utilizar combustibles sólidos, cabría hablar de necesidad de hacerlo, es decir, de algo no deseado, a lo que, no obstante, tal vez obliguen las circunstancias futuras. En ese sentido - concluyó-, toda previsión presente quizá sea poca.

3. Después intervino el Sr. LOPEZ SOLER para preguntar más específicamente sobre la posibilidad de utilizar combustibles pobres en los hornos con parrilla.

Contestaron los Sres. RITZMANN y MANNS, éste último haciendo también las veces de traductor, diciendo que se estaban llevando a cabo ensayos durante meses para poder emplear combustibles pobres en la parrilla LEPOL, y que parecía ser por los resultados que tal posibilidad existe, aunque en una medida mucho más limitada que en el caso de hornos con intercambiadores.

Preguntó después el Sr. LOPEZ SOLER en qué parte de la instalación se añadían estos combustibles, siéndole respondido que en la cámara caliente. Siguió preguntando si, al hacerlo así, no se produciría en dicha zona un sobrecalentamiento, en relación con lo que sucede en el régimen normal de marcha del horno, y si ello no daría lugar a un mal aprovechamiento real del calor extra aportado así.

Los Sres. RITZMANN y MANNS respondieron que, efectivamente, se produce una elevación de temperatura, ya que lo que se pretende es aumentar el grado de descarbonatación; pero que en la medida correspondiente se descarga de trabajo al horno rotatorio, con lo cual el consumo específico de calor no aumenta de forma sustancial.

A una nueva pregunta del Sr. LOPEZ SOLER acerca de si existía experiencia de añadir en el granulador carbón pobre molido, se respondió que los resultados no habían sido buenos, porque el combustible se desgasifica y quema ya en parte en las zonas más frías de la parrilla, con lo cual lo único que se consigue es aumentar la temperatura de los gases de escape, siendo así que lo que se pretende es aumentar el grado de descarbonatación, y esto se logra sólo en las zonas más calientes de la parrilla, por ser necesario para ello una temperatura mínima determinada.

4. En relación con todo lo expuesto, el Sr. CALLEJA preguntó que, puesto que los carbones pobres de que se hablaba, lógicamente contienen una proporción elevada de cenizas, si al desgasificarse en la zona de la parrilla no podrían producir pegaduras en ésta, incluso anillos en el horno, sobre todo si la proporción y composición de las cenizas son tales que facilitan la formación de dichas pegaduras y anillos. 
A esto fue respondido por los Sres. RITZMANN y MANNS que en las dos instalaciones que estaban ya en marcha, una desde hacía años y otra desde hacía unos siete meses, no se había observado por el momento ninguno de tales efectos.

5. El Sr. PONS DE VIÑALS preguntó acto seguido si para la combustión de carbones de baja calidad, o de desecho, se requería algún tipo de instalación especial, o si se podía utilizar la actual existente en un sistema con intercambiador de calor. Se respondió que en tal caso no se había hecho precisa ninguna modificación, y que el carbón se inyectaba prácticamente en el tubo ascendente de la etapa más baja de los ciclones, y que se tenía en cuenta lógicamente las precauciones que tales carbones requieren en orden a protección contra explosiones, etc.

El Sr. PONS DE VIÑALS siguió preguntando si sería factible utilizar el procedimiento inglés, en fase de intento, de inyectar como combustible de baja calidad y barato las basuras, resolviendo con ello el doble problema de ayudar al horno con una aportación calorífica, y de eliminar los problemas de acumulación, eliminación y contaminación que crean las basuras en las ciudades.

Contestaron los Sres. RITZMANN y MANNS, en primer lugar, que cualquier respuesta tendría repercusiones grandes y, en segundo lugar, que en principio, debería de ser posible. Pero que ello exigiría resolver bastantes problemas de preparación de las basuras para su transporte y utilización, así como de adecuación de su finura y de conocimiento de su composición, en relación con la composición del crudo en el que se pretendiese utilizarlas.

6. El Sr. BALAGUER mencionó el tema del azufre de los carbones, aclarando que en los primeros años cuarenta hizo la experiencia de tratar de aprovechar como combustible el 10 ó 12 por ciento de carbón contenido en unas pizarras de terraplenes de unas minas de carbón, utilizándolas como componente del crudo, y mediante la adición de la caliza correspondiente. Y sucedió —continuó diciendo el Sr. BALAGUER-, que estas pizarras parcialmente combustibles, se quemaban en parte en la base de la chimenea, donde se llegaba a alcanzar temperaturas de 1.100 a $1.200^{\circ} \mathrm{C}$, tal y como se dice que puede ocurrir ahora, y sin que ello sirviera para nada. Y que en parte se acababan de quemar en la zona trasera del horno, sin que ello influyese de ningún modo en la calcinación, coincidiendo también con lo que se había dicho que sucedía.

Pero además, —prosiguió-, estas pizarras (como los carbones malos en general) tenían una buena dosis de azufre, el cual en el horno formaba sulfuro cálcico que no llegaba a oxidarse y se mantenía como tal, y sulfuro férrico, los cuales quedaban en el clínker. Con todo ello resultaba un cemento de color verde y expansivo.

Concluyó preguntando el Sr. BALAGUER qué experiencia había acerca de estos hechos y sobre la utilización de carbones o combustibles de las características de los mencionados, en los actuales sistemas de hornos de suspensión de gases, no existentes aún en la época de su intento.

A ello respondieron los Sres. RITZMANN y MANNS que entre este intento y lo que se pretende ahora hay una diferencia fundamental, y es que ahora se añade el combustible en una zona de temperaturas altas, entre los 800 y $900^{\circ} \mathrm{C}$, y con oxígeno suficiente y uniformemente repartido en la suspensión de gases. $\mathrm{Y}$ que en tales condiciones la combustión es muy rápida y completa y no hay lugar para efectos reductores como los que sin duda se habrían producido en el caso de la experiencia del Sr. BALAGUER.

Este añadió que bien pudiera haber sucedido así, al menos en parte, porque en dicha experiencia se producía en primer lugar una destilación del azufre que, antes de la combustión de éste, daba lugar a la formación del sulfuro cálcico que ya no se oxidaba después y quedaba como tal en el clínker. 
Dijo también el Sr. BALAGUER que había otro aspecto a considerar, y era el de que si se trataba de hacer el aprovechamiento de los carbones pobres y con azufre en un horno LEPOL, a través de la granulación del crudo, sucedería precisamente lo mismo que en su experiencia: que el sulfuro cálcico quedaría dentro de los gránulos del clínker. Y además -añadió-, el exceso de cenizas, tal y como se movilizan y sitúan en los gránulos, formarían alrededor de éstos una capa superficial, que al no neutralizarse por falta de suficiente difusión darían lugar a una desdosificación de la composición del crudo y a una heterogeneidad de la del clínker.

Los Sres. RITZMANN y MANNS dijeron que es cierto que tales efectos son, al menos, de temer, pero que los ensayos efectuados no han llegado aún a su final para poder decir si dichos efectos tienen lugar o no. Añadieron que, en cuanto a la difusión del azufre, con seguridad ésta tendría lugar en una zona fría de la parrilla, con consecuencias fastidiosas; y en cuanto al recubrimiento de los gránulos con cenizas, que era algo que hacía años ya ocurría en el horno cuando se quemaba exclusivamente carbón, y que tal vez no fuera tan de temer.

En relación con esto último el Sr. BALAGUER dijo que cuando los carbones tienen contenidos bajos de cenizas la cosa no tiene importancia; pero que cuando éstas son abundantes - y en épocas pasadas se habían quemado carbones con 40 y $45 \%$ de cenizasel cambio de composición en las cortezas de los gránulos era muy notable. A esto se respondió que en el caso de la parrilla LEPOL no existiría ese peligro, ya que con tal sistema sólo se podría utilizar de un 10 a un $15 \%$ de carbón pobre.

\%. Insistiendo sobre el mismo tema, el Sr. CALLEJA quiso agregar algo, diciendo que a los efectos que se habían señalado tal vez hubiera que añadir otro adicional. $Y$ es - dijo-, el resultante de que si en una zona determinada del horno, de baja temperatura relativamente hablando, se forman sulfuros cálcico y férrico, y eventualmente sulfuros de carácter más reducido, como por ejemplo el ferroso, particularmente estos últimos tienen una fusibilidad mayor que los otros y que los correspondientes compuestos no reducidos o menos reducidos. $Y$ entonces, al llegar a las zonas de mayor temperatura del horno, podían formar eutécticos de puntos de fusión mucho más bajos, como consecuencia de lo cual se podrían crear cantidades de fase líquida mayores que las correspondientes al sistema normal del clínker portland. Esto, a su vez, por una parte puede modificar (no sé en que sentido, si haciéndolo aumentar o disminuir de espesor y consistencia -dijo el Sr. CALLEJA-), el revestimiento del horno en una determinada zona; y por otra parte - prosiguió-, puede alterar la granulometría del clínker, probablemente haciendo que se formen gránulos de bastante mayor tamaño (e incluso bolas y conglomerados) que en el caso de operar en condiciones normales ordinarias, sin aportación de combustibles pobres y abundantes en azufre elemental o al estado de sulfuro.

A esto se contestó que había que procurar que en el horno no se dieran condiciones reductoras, únicas en las que se forman compuestos reducidos, disponiendo de oxígeno y de temperatura suficientes para quemar completamente y en el tiempo preciso todo el combustible pobre que se añadiese en las zonas indicadas de los hornos LEPOL y con intercambiadores.

Y a lo que precede respondió a su vez el Sr. CALLEJA diciendo que si no se procuraba tomar esas precauciones, o si, haciéndolo y a pesar de ello, no se conseguía evitar tener unas ciertas condiciones reductoras durante un tiempo en una zona crítica del horno, insistía en preguntar si los Sres. RITZMANN, MANNS y RAMOS opinaban que podría suceder lo señalado por él; que, desde su punto de vista, era previsible que pudiera ocurrir, pero que no tenía seguridad de ello, y por lo mismo requería el juicio de quienes pudieran tener una experiencia más o menos aproximada al tema. 
Los Sres. RITZMANN y MANNS se limitaron a contestar que la experiencia de una instalación en funcionamiento había demostrado que no se producían tales fenómenos.

8. A continuación el Sr. VARGAS preguntó si, habiendo de ir en exceso el aire para la combustión del carbón añadido, no existiría el peligro de tener una mala combustión en el horno. Se respondió que era precisamente al contrario, ya que debido al gran exceso de aire la llama era más fuerte y corta y la combustión más intensa, a lo cual el Sr. VARGAS dijo que, en su opinión, si era preciso introducir todo el aire suficiente, no sólo para la propia combustión ordinaria, sino además para la otra combustión del carbón que se introduce en una zona más o menos trasera del sistema, y todo el aire y su exceso había de entrar a través del horno, el aire sobrante y en exceso en la zona más delantera alargaría la llama y la enfriaría.

Los Sres. RITZMANN y MANNS respondieron que la reducción de temperatura no se producía en la llama ni en la zona de la llama, sino más bien detrás de ésta, al unirse los gases de combustión con el aire en exceso. Y que, en definitiva, las instalaciones que estaban en marcha demostraban que era posible la utilización de los combustibles pobres y en las condiciones señaladas, sin que se produjeran los efectos nocivos de llamas largas, frías y difíciles de controlar, y sin que la clinkerización sufriese.

El Sr. CALLEJA dijo que, admitiéndolo así, si no sería a costa del inconveniente de tener que utilizar un mayor volumen de aire primario para la combustión. Al ser respondido que la proporción de aire primario era la misma, el Sr. VARGAS preguntó que de dónde procedía entonces el exceso de aire. Los Sres. RITZMANN y MANNS respondieron que se trataba de aire secundario del enfriador, ya que el enfriamiento tenía que llevarse a cabo como si todo el crudo, y no sólo parte de él, se hubiese cocido con la llama del horno.

A esto sugirió el Sr. VARGAS si no sería mejor mezclar el carbón pobre con el fuel-oil, de forma que ambos ardieran como único combustible en la llama del horno, tal y como se venía haciendo ya en algunas fábricas.

Los Sres. RITZMANN y MANNS respondieron diciendo que, en principio se podría hacer así, pero que entonces se produciría seguramente el efecto del recubrimiento de los gránulos por las cenizas, observado por el Sr. BALAGUER, ya que éstas no se mezclarían homogéneamente con el crudo; por el contrario - añadieron-, la eficacia de la mezcla en suspensión es mucho mayor, con lo cual el crudo y el carbón entran ya en el horno homogéneamente mezclados. Y además -adujeron-, en el otro caso existiría el peligro de que las partículas de ceniza, antes de haber reaccionado con el crudo, se adhiriesen al recubrimiento del horno incrementando excesivamente la costra, formasen anillos, etc.

9. A continuación el Sr. FERNANDEZ MOLINA preguntó acerca de las posibilidades de inyectar el polvo de los filtros electrostáticos mezclado con el fuel-oil para evitar la formación de concreciones en los ciclones, en el caso de los sistemas intercambiadores en suspensión.

Respondieron los Sres. RITZMANN y MANNS diciendo que era dudoso que tal acción pudiese ayudar en algo, ya que equivaldría a introducir los álcalis una vez decantados en el filtro, alimentando con ello el circuito de álcalis en el horno.

A esto dijo el Sr. FERNANDEZ MOLINA que, puesto que de todos modos el polvo con sus álcalis había que introducirlo, y puesto que el manantial de azufre era el combustible, al realizar dicha introducción los álcalis se volatilizan con rapidez en la llama y su reacción con el azufre en fase gaseosa sería también rápida, formándose sulfatos alcalinos y cálcico. Y que en el caso de formación preferente de sulfatos no volátiles, por 
ella se podría eliminar eventualmente el riesgo de las concreciones, siempre a costa de enriquecer el clínker en sulfatos. Preguntó si existía tal posibilidad.

Los Sres. RITZMANN y MANNS dijeron que no se atrevían a responder en sentido afirmativo ni negativo, y que sería preciso hacer ensayos para determinar lo que sucedería. El Sr. FERNANDEZ MOLINA aclaró que él se refería a la inyección de polvo en el propio horno, en la fuente principal de combustible, a lo que se respondió que la idea no parecía muy aceptable y que, aunque realmente se estaba procediendo así en algunas instalaciones, existía evidentemente el mismo peligro que ya se había citado a propósito de la incorporación de las cenizas de los carbones, y que no atraía la idea de introducir el polvo en la llama.

El Sr. FERNANDEZ MOLINA insistió en que el polvo en la llama aumentaba el poder emisivo de ésta, y los Sres. RITZMANN y MANNS dijeron que sí, si se trataba de una llama de gas; pero que se disponía de otros medios para combinar los álcalis con los sulfatos.

10. Finalmente el Sr. SOLER, en relación con el tema de aumentar en una quinta etapa el sistema intercambiador, preguntó si en tal sentido se habría hecho algún proyecto de modificación de alguna instalación existente; y aclaró que lo preguntaba pensando en los cambios que ello comportaría en cuanto a la obra civil.

Se le respondió que, en efecto, se habían hecho estudios y varios proyectos para transformar algunas instalaciones ya existentes, añadiéndoles una etapa más, pero que no se había hecho ninguna realización al respecto; que lo que sí se había hecho era suministrar una nueva planta con cinco etapas en el intercambiador, la cual no estaba aún en funcionamiento.

Con esto se dió por terminado este Coloquio. 